\title{
Serología del virus de la hepatitis B: para múltiples escenarios, múltiples exámenes
}

\section{Serology of hepatitis B virus: multiple scenarios and multiple exams}

William Otero, MD, ${ }^{1}$ Julián Parga, MD, ${ }^{2}$ Johanna Gastelbondo, MD. ${ }^{2}$

\footnotetext{
Profesor titular de Medicina, Unidad de Gastroenterología, Universidad Nacional de Colombia, Hospital Universitario Nacional de Colombia. Gastroenterólogo Clínica Fundadores. Bogotá D. C., Colombia.

2 Internista, residente de Gastroenterología, Universidad Nacional de Colombia, Hospital Universitario de Colombia. Bogotá D. C., Colombia.

Fecha recibido: $\quad 05-02-18$ Fecha aceptado: 12-03-18
}

\begin{abstract}
Resumen
El virus de la hepatitis $B(V H B)$ tiene un gran impacto mundial. No obstante la disponibilidad de la vacuna, 2000 millones de personas se han infectado agudamente y, de ellos, 240 millones persisten crónicamente infectados. La infección tiene diferentes formas de presentación tales como infección aguda, infección crónica, infección oculta y reactivación cuando hay inmunosupresión. Así mismo, hay marcadores muy sensibles como el anticore, cuya positividad puede tener diversos significados. El recientemente descrito antígeno relacionado con el antígeno core es un marcador emergente que podría reemplazar al ácido desoxirribonucleico (ADN) viral. En la presente revisión se discuten los exámenes de laboratorio necesarios para el diagnóstico de los diferentes escenarios de la infección.
\end{abstract}

\section{Palabras clave \\ Virus B, infección oculta, anticore, reactivación.}

\begin{abstract}
Hepatitis B virus (HBV) has an enormous global impact. Despite the availability of a vaccine, two billion people have been acutely infected. Of these, 240 million remain chronically infected. The infection has different forms of presentation including acute infections, chronic infections, hidden infections, and reactivation when there is immunosuppression. Similarly, there are very sensitive markers such as anti-core, but a positive test can have different meanings. This recently described antigen which is related to the core antigen is an emerging marker that could replace viral DNA. In this review we discuss the laboratory tests necessary for diagnosing the various scenarios of the infection.
\end{abstract}

Keywords

$B$ virus, hidden infection, anti-core, reactivation.

\section{INTRODUCCIÓN}

El virus de la hepatitis B (VHB) representa un problema de salud en el mundo. Se estima que 2000 millones de personas han estado expuestas al virus y 240 millones siguen crónicamente infectadas (1), siendo la infección viral crónica más frecuente (2). El 15 \%-40 \% de los que tienen infección crónica progresa a cirrosis y sus complicaciones, incluido hepatocarcinoma (3). En 2013 produjo
686000 muertes (3), esta cifra representó un incremento de $33 \%$ entre 1990 y el 2013 (3). En 2005 la prevalencia en Centroamérica era menor del $2 \%$ y en Suramérica era del $2 \%$ al $4 \%$ (3). En éste último se producen 400000 casos nuevos cada año (3). No obstante las recomendaciones para la vacunación universal contra el VHB, esta profilaxis no ha sido ampliamente implementada en los países con mayor prevalencia por falta de recursos económicos y logísticos (3). 
El VHB es miembro de la familia Hepadnaviridae, cuyos miembros son virus de ácido desoxirribonucleico (ADN) pequeños (3200 pares de bases), hepatotropos, con envoltura externa $(4,5)$. El ADN es parcialmente de doble cadena y de cadena simple, $y$ tiene una plantilla transcripcional que es el ADN circular covalentemente cerrado ( $\mathrm{ADNccc}$ ), el cual se introduce muy rápidamente en el núcleo del hepatocito durante la infección aguda (6). Pertenece al género Orthohepadnavirus, que infecta mamíferos, y el género Avihepadnaviridae, que afecta a las aves (4). Se considera que este virus se originó en África hace por lo menos 40 000 años (6). Tiene 10 genotipos (A-J), el A es frecuente en Norteamérica, Norte de Europa y África; el B y C, en Asia $(4,7)$. En algunos estudios se ha encontrado asociación entre el genotipo y la progresión de la enfermedad y respuesta al interferón (4). Los genotipos $\mathrm{C}$ y $\mathrm{F}$ se asocian más frecuentemente con el hepatocarcinoma, así como también algunos subgenotipos del tipo A. Por su parte, el genotipo A tiene riesgo de progresar a infección crónica (4, 7); sin embargo, cualquier infección aguda puede progresar a infección crónica, independientemente del genotipo (4).

Se transmite fundamentalmente por vía sexual, perinatal y por rutas parenterales permucosa o percutánea a través de lesiones con elementos cortopunzantes contaminados con sangre infectada (8). Esta última forma de transmisión incluye las punciones accidentales en los ambientes hospitalarios con instrumental médico quirúrgico contaminado, procedimientos de manicura, pedicura, tatuajes, drogadicción intravenosa (al compartir jeringas contaminadas) y piercings, entre otros (8). La contaminación con tales procedimientos ha disminuido conforme se han divulgado los riesgos inherentes a los mismos, se ha implementado la esterilización de instrumentales médicos y se ha prohibido el reuso de agujas (9). De igual manera se ha logrado disminuir la transmisión sexual con la educación acerca de la utilización de medidas de protección sexual $(8,9)$. El 95\% de los casos de transmisión vertical ocurre durante el parto vaginal y el $5 \%$ por transmisión intrauterina (8). El espectro clínico de la infección por el VHB incluye hepatitis aguda (HBA), hepatitis crónica (HBC) e infección oculta (10). Así mismo, puede producir cirrosis, hepatocarcinoma y compromiso de órganos extrahepáticos (11-14).

Por el impacto y la complejidad de la infección por este virus, en la presente revisión se discuten los diferentes exámenes utilizados para diagnosticar la infección en los diferentes escenarios encontrados en la práctica diaria (Figura 1).

\section{Hepatitis B aguda}

El diagnóstico se establece con la positividad simultánea del antígeno de superficie (HBsAg) y del anticore inmunoglobulina M (IgM) (15). El HBsAg es la marca serológica

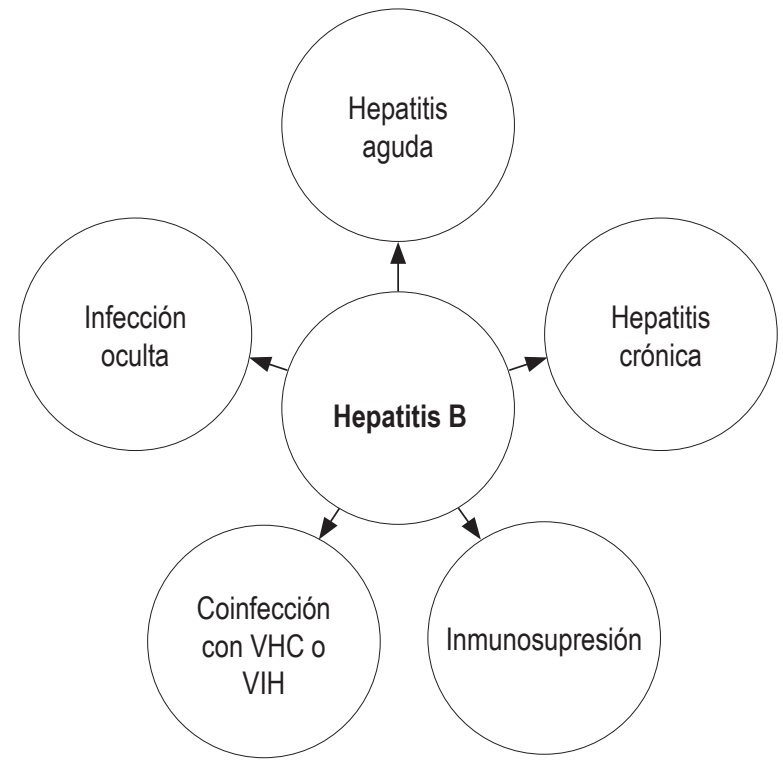

Figura 1. Escenarios para la serología del VHB.

de la infección por el VHB (15). Sin embargo, hay casos en los cuales el HBsAg desaparece rápidamente sin la aparición del anticuerpo antisuperficie, lo cual corresponde al período de ventana inmunológica, en la cual la única evidencia de infección aguda por el VHB es el anticore $\operatorname{IgM}(15)$. Este anticuerpo aparece 2 semanas después del HBsAg y puede persistir hasta 2 años (16). El HBsAg es detectable 1 a 10 semanas después del contacto infectante (2). La detección del anticore IgM coincide con los síntomas generales y el aumento de las aminotransferasas (14).

La resolución de la HBA se caracteriza por desaparición del HBsAg, aparición de anticuerpos anti-HBsAg, anticore inmunoglobulina $\mathrm{G}(\mathrm{IgG})$ y normalización de los niveles de alanina-aminotransferasa (ALT) $(14,15)$. Este perfil, en realidad, indica una cura aparente, que se ha definido como curación funcional (17). Se ha encontrado que, no obstante la presencia de marcadores de desaparición de la infección, en el núcleo del hepatocito persiste el ADNccc, como un episoma o minicromosoma a partir del cual se genera ácido ribonucleico (ARN) y de este $\mathrm{ADN}$, iniciándose la replicación viral (18). Este ADNccc persiste indefinidamente en el huésped después de las primeras 24 horas de la infección (18). Ese reservorio del VHB puede reiniciar su replicación si los mecanismos inmunológicos de defensa son bloqueados, como sucede con los diferentes tratamientos inmunosupresores, ya que la inmunidad del huésped controla esas células infectadas (19).

Recientemente, el concepto de curación funcional se ha redefinido como la pérdida del HBsAg con o sin aparición 
del anticuerpo anti-HBsAg, $A D N$ indetectable en suero, pero con persistencia del $A D N c c c(6,13)$. En contraste con la curación funcional, la curación total es la curación funcional más la eliminación del $\operatorname{ADNccc}(20,21)$. En la actualidad es imposible curar la infección por el VHB porque los medicamentos disponibles no pueden eliminar el ADNccc y solo suprimen la replicación viral $(19,22)$. La eliminación del ADNccc es la meta ideal del tratamiento de la infección crónica por el VHB $(6,19)$.

Cuando hay reactivación del VHB en una infección crónica, el anticore IgM puede ser positivo en $10 \%-15 \%$ de los pacientes (16), indistinguible de una infección aguda (15, $16,23,24)$. Algunas características serológicas pueden ayudar a diferenciarlas. En la infección aguda, la IgM es pentamérica con un peso molecular de $19 \mathrm{~S}$ y en la crónica es monomérica con un peso molecular de 7-8 S (16). Títulos mayores de 1:1000 se ven en el $80 \%$ de las infecciones agudas, con una sensibilidad y especificidad de $96,2 \%$ y 93,1 $\%$, respectivamente, cuando se determinan por inmunoensayo enzimático (23). Títulos de IgM menores de 1:1000 se ven en el $70 \%$ de los casos de hepatitis B crónica (HBC) que tiene exacerbación aguda $(23,24)$.

\section{Hepatitis B crónica}

La infección crónica por el VHB (HBC) existe cuando el HBsAg persiste positivo después de 6 meses de una infección aguda $(8,9,14)$. Su aparición depende de la interacción entre el VHB y el sistema inmune. La probabilidad se aumenta con la inmadurez inmunológica o los estados de inmunosupresión (25). En el recién nacido, aparece en el $98 \%$ de los infectados; en los niños de 1 a 5 años, en el 20 $\%-30 \%$, contrastando con menos del $5 \%$ en los adultos inmunocompetentes $(26,27)$. Un resumen de la interpretación de los diferentes hallazgos de la serología del VHB se muestran en la Tabla 1.

Tabla 1. Serologías típicas del VHB

\begin{tabular}{lccc}
\hline & HBsAg & Anticore & $\begin{array}{c}\text { Anticuerpos } \\
\text { antisuperficie }\end{array}$ \\
\hline Infección aguda & Positivo & $\operatorname{lgM}$ positivo & Negativo \\
Infección resuelta & Negativo & $\lg$ positivo & Positivo \\
Infección crónica & Positivo & $\lg$ positivo & Negativo \\
Vacunado & Negativo & Negativo & Positivo \\
Susceptible & Negativo & Negativo & Negativo \\
\hline
\end{tabular}

La Asociación Europea para el Estudio del Hígado (EASL) clasifica la HBC en 4 tipos de acuerdo con la positividad del antígeno "e" y la presencia o no de enfermedad hepática (28) (Tabla 2). Esta nueva clasificación reemplaza la nomenclatura anterior de portador inactivo, inmunotolerante, entre otras.

El tratamiento está indicado en las siguientes situaciones (28):

1. Todos los pacientes con o sin antígeno "e" que tengan hepatitis crónica (ADN >2000 UI/mL, ALT por encima del límite superior normal y/o necroinflamación hepática moderada o fibrosis);

2. Pacientes con cirrosis compensada o descompensada, independientemente del nivel de ADN o de ALT;

3. Pacientes con $\mathrm{ADN}>20000 \mathrm{UI} / \mathrm{mL}$ y ALT $>2$ veces el límite superior normal, independientemente del grado de fibrosis;

4. Pacientes con antígeno "e" positivo e infección crónica (ALT persistentemente normal) y niveles elevados de $\mathrm{ADN}$ si son mayores de 30 años, independientemente de la severidad de la histología hepática;

5. Pacientes con infección crónica, antígeno "e" positivo o negativo, que tengan historia familiar de hepatocarcinoma, cirrosis y manifestaciones extrahepáticas, aunque no cumplen las indicaciones típicas de tratamiento.

Se recomienda que los pacientes con $\mathrm{HBC}$ que no cumplen los criterios mencionados sean controlados periódicamente según las siguientes características:

1. Menores de 30 años con antígeno "e" positivo, monitorización cada 3-6 meses;

2. Antígeno "e" negativo y $\mathrm{ADN}<2000 \mathrm{UI} / \mathrm{mL}$ deben ser monitorizados cada 6-12 meses y cuando el nivel de $\mathrm{ADN}$ es $>2000 \mathrm{UI} / \mathrm{mL}$, la monitorización se recomienda cada 3 meses durante el primer año y después cada 6 meses.

\section{INFECCIÓN OCULTA POR VHB (IOVB)}

La IOVB se sospechó en los setenta y, debido al interés por la misma, se produjo una publicación sobre el tema en 1999 (29). Inicialmente se definió cuando el HBsAg es negativo y $A D N$ del VHB es positivo en el hígado, con o sin $A D N$ detectable en el suero $(30,31)$. Sin embargo, por la dificultad y riesgos de la biopsia hepática para identificar el ADN del VHB en ese tejido, y por la falta de estandarización para el ADN hepático, se aceptó que el $\mathrm{ADN}$ de suero reemplazara al ADN hepático $(31,32)$. Además, la determinación en suero tiene adecuada estandarización y sensibilidad $(31,32)$. La carga viral usualmente es menor de $200 \mathrm{UI} / \mathrm{mL}$ y en más del $90 \%$ es $20 \mathrm{UI} / \mathrm{mL}$ (33). Las alteraciones básicas de la IOVB son HBsAg negativo y ADN positivo en suero (30). Adicionalmente, puede ser seropositiva o seronegativa si tiene o no anti-HBc IgG y/o anticuerpos antisuperficie positivos $(30,34,35)$. La mayoría de pacientes seropositi- 
Tabla 2. Tipos de HBC

\begin{tabular}{lcccc}
\hline & \multicolumn{2}{c}{ Antígeno "e" positivo } & \multicolumn{2}{c}{ Antígeno "e" negativo } \\
\cline { 2 - 5 } & Infección crónica & Hepatitis crónica & Infección crónica & Hepatitis crónica \\
\hline $\mathrm{HBsAg}$ & Alto & Alto/intermedio & Bajo & Intermedio \\
$\mathrm{HBeAg}$ & Positivo & Positivo & Negativo & Negativo \\
$\mathrm{ADN}$ virus B & $>10^{7} \mathrm{UI} / \mathrm{mL}$ & $10^{4}-10^{7} \mathrm{Ul} / \mathrm{mL}$ & $<2000 \mathrm{UI} / \mathrm{mL}$ & $>2000 \mathrm{UI} / \mathrm{mL}$ \\
$\mathrm{ALT}$ & Normal & Elevada & Normal & Elevada \\
Enfermedad hepática & Ninguna/mínima & Moderada/severa & Ninguna & Moderada/severa \\
Terminología antigua & Inmunotolerante & Inmunorreactivo HBeAg $(+)$ & Portador inactivo & Hepatitis crónica HBeAg $(-)$ \\
\hline
\end{tabular}

vos tuvo infección crónica y el HBsAg desapareció espontáneamente $(34,35)$. El HBsAg desaparece anualmente en el 0,5\%-2,2 \% (31). Los seropositivos tienen un perfil de citocinas diferentes a los seronegativos (36). Los primeros tienen menor expresión de interferón gamma (IFN- $\gamma$ ) de células T específicas de VHB (36). Por otras características vistas en modelos animales de IOVB, se presume que los seropositivos y seronegativos tienen diferentes formas de contagio $(37,38)$. Los seropositivos son la mayoría de los pacientes $(80 \%)(34)$.

La EASL tipifica la IOVB en la quinta fase de la infección crónica por el VHB, caracterizada por la pérdida del HBsAg y positividad para el anticore con o sin anticuerpos antisuperficie (30). En esos pacientes, el ADNccc es el responsable de la IOVB (30-35). La detección del ADN durante el período de ventana serológica de la infección aguda, cuando el HBsAg es negativo, es una "falsa infección oculta" por el VHB (30).

Las consecuencias de una IOVB incluyen la posibilidad de transmisión de la infección por transfusiones, inducción de hepatocarcinoma y reactivación de la infección con cualquier tipo de inmunosupresión $(31,37)$. En inmunocompetentes, la IOVB es inofensiva. Cuando hay reactivación, reaparecen los marcadores típicos de una infección manifiesta (38). Los exámenes iniciales para investigar la IOVB son el HBsAg y el anti-HBc total. Por definición, el HBsAg debe ser negativo e independientemente del resultado del anticore total, se debe investigar el ADN del VHB. Sin embargo, para evitar retrasos en el diagnóstico, esos exámenes deben hacerse simultáneamente. Si se cumplen los criterios mencionados de IOVB, se establece el diagnóstico (30). Si todos los exámenes son negativos, el paciente es susceptible y debe ser vacunado contra la HB (39-41).

La IOVB es asintomática, por lo cual debe investigarse en los siguientes pacientes de alto riesgo (42): infectados con virus de la inmunodeficiencia humana (VIH), hepatitis C crónica, inmunosuprimidos, hepatocarcinoma, hemodiálisis, cirrosis criptogénica, enfermedad hepática crónica sin causa identificada, trasplantados o programados para trasplante y los que recibirán inmunosupresión de cualquier tipo (42).

El riesgo de la IOVB en los pacientes con hepatitis C (VHC) es que, al eliminar al virus $\mathrm{C}$ con los antivirales de acción directa, se puede reactivar el VHB y producir insuficiencia hepática aguda con severidad variable, que puede incluir la muerte (43-45). En 2016 la Food and Drug Administration (FDA) hizo una alerta después de recopilar 24 casos entre 2013-2016 (46). En la mitad de esos pacientes la reactivación se identificó oportunamente $\mathrm{y}$ fueron tratados inmediatamente con tenofovir/entecavir, con lo que se logró una mejoría clínica y disminución de la carga viral. Los otros pacientes recibieron tratamiento tardío, 2 fallecieron y 1 recibió trasplante hepático (46). Por las consecuencias mencionadas, la FDA recomienda que todos los pacientes con infección crónica por el virus $\mathrm{C}$ en tratamiento se les debe solicitar $\mathrm{ADN}$ del VHB y vigilarlos estrechamente con perfil hepático, y recomendarles que consulten inmediatamente si aparecen síntomas de daño hepático (ictericia, malestar, fiebre, entre otros). Si se identifica reactivación, deben recibir tratamiento urgente con tenofovir o entecavir (47).

\section{ANTI-HBC AISLADO}

El antígeno core es un componente interno del VHB; sin embargo, es el más inmunogénico de todos (48). Los anticuerpos contra el antígeno core se producen en todos los pacientes infectados, independientemente de que resuelvan o no la infección aguda (48). Como se mencionó previamente, en la infección aguda, el anticuerpo es IgM y, conforme la infección se resuelve, los niveles del mismo disminuyen progresivamente y son reemplazados por los de la clase IgG, los cuales pueden persistir durante toda la vida del paciente $(49,50)$. Por ese comportamiento se consideran los marcadores serológicos más confiables de la infección por el VHB y se denominan los marcadores epidemiológicos de la misma (49). 
El hallazgo de anticuerpos anticore total, sin HBsAg y anticuerpos antisuperficie, se denomina anticore aislado $(50,51)$, el cual ocurre principalmente en grupos de riesgo: usuarios de drogas recreativas endovenosas, VHC, VIH, hemodiálisis, receptor de trasplante de órgano sólido y embarazadas (51).

La prevalencia del anticore varía de $1 \%-32 \%(50)$. Su hallazgo representa un reto para el clínico, ya que puede corresponder a diferentes situaciones (51):

1. Infección resuelta (lo más frecuente);

2. Falso positivo, situación frecuente en personas de regiones con baja prevalencia del VHB $(50,51)$;

3. Infección aguda, en la cual el anticore IgM explica la positividad del anticore total;

4. Infección crónica con niveles bajos de replicación, este es el grupo de mayor riesgo en caso de requerir inmunosupresión (52);

5. Coinfección con VHC (53-57) o VIH (50, 58-60).

Los mecanismos implicados se explican a continuación.

\section{Falso positivo}

Aunque los inmunoensayos actualmente utilizados para identificar el anticore total son altamente específicos, durante su ejecución se pueden producir errores y dar resultados incorrectos (50). Por lo anterior se recomienda confirmar sus resultados en una segunda muestra de suero $(50,61)$. El método relacionado con falsos positivos es el inmunoensayo enzimático, menos específico que el radioinmunoensayo $(62,63)$, pero este último no está disponible en los diferentes laboratorios (50). Por esta razón, la recomendación de repetir la prueba utilizándolo como un segundo método rara vez se podría realizar (51).

\section{Coinfección con VHC o VIH (54-60)}

La coinfección con el VHC o el VIH puede interferir con replicación del VHB y la respuesta inmunológica del huésped, al inducir una regulación negativa de los genes del VHB o modular la respuesta inmunológica contra el VHB (50).

Con el VHC, se ha demostrado una inhibición recíproca entre ambos virus $(54,55)$. Las proteínas centrales del VHC inhiben la replicación del VHB y la síntesis del HBsAg (55, 57). En la infección VIH, el único marcador de la infección por el VHB puede ser el anticore aislado $(50,58)$. Por lo anterior, se recomienda que cuando se investigue el VHB en un paciente con VIH se incluya el ADN del VHB.

La evaluación de un paciente con anticore positivo se muestra en la Figura 2 (61).

Una síntesis del significado del anticore aislado se muestra en la Tabla 3.

\section{REACTIVACIÓN DE LA INFECCIÓN}

La reactivación del VHB se describió hace más de 50 años en individuos que aparentemente se habían curado de la infección aguda y recibieron inmunosupresión $(64,65)$. La inmunocompetencia controla el VHB y, cuando esa se pierde, el virus se puede reactivar $(66,67)$. La pérdida de la inmunocompetencia puede ser espontánea o inducida por inmunosupresores $(67,68)$.

Las asociaciones científicas tienen diferentes recomendaciones sobre los exámenes del VHB que deben solicitarse antes de iniciar inmunosupresión (28, 68-70) (Tabla 4).

Esas diferencias probablemente se deben a la falta de estudios prospectivos y a la diversa prevalencia del VHB en los continentes o países (69). En la guía del Pacífico asiático no se solicita el anticore total, porque en esa región el VHB

Tabla 3. Anticore aislado

\begin{tabular}{|c|c|}
\hline $\begin{array}{l}\text { Infección aguda resuelta } \\
\text { Clase IgG }\end{array}$ & $\begin{array}{l}\text { El antígeno antisuperficie puede ser positivo o negativo. En este último caso, los niveles del antisuperficie } \\
\text { han disminuido a niveles indetectables. }\end{array}$ \\
\hline $\begin{array}{l}\text { Período de ventana inmunológica } \\
\text { Clase IgM }\end{array}$ & Ha ocurrido un aclaramiento muy rápido del HBsAg y aún no ha aparecido el anticuerpo antisuperficie. \\
\hline $\begin{array}{l}\text { Infección crónica } \\
\text { Clase lgG }\end{array}$ & El HBsAg será positivo y el antisuperficie negativo. \\
\hline Coinfección con VHC o con VIH & EI VHC inhibe la replicación del VHB y la producción de HBsAg. En la infección por VIH sucede algo similar. \\
\hline Infección oculta & HBsAg negativo, ADN positivo, antisuperficie (+) o (-) \\
\hline Falso positivo & $\begin{array}{l}\text { Errores en la ejecución del inmunoensayo enzimático. El radio-inmunoensayo es más específico, pero no } \\
\text { está disponible en los laboratorios. }\end{array}$ \\
\hline
\end{tabular}




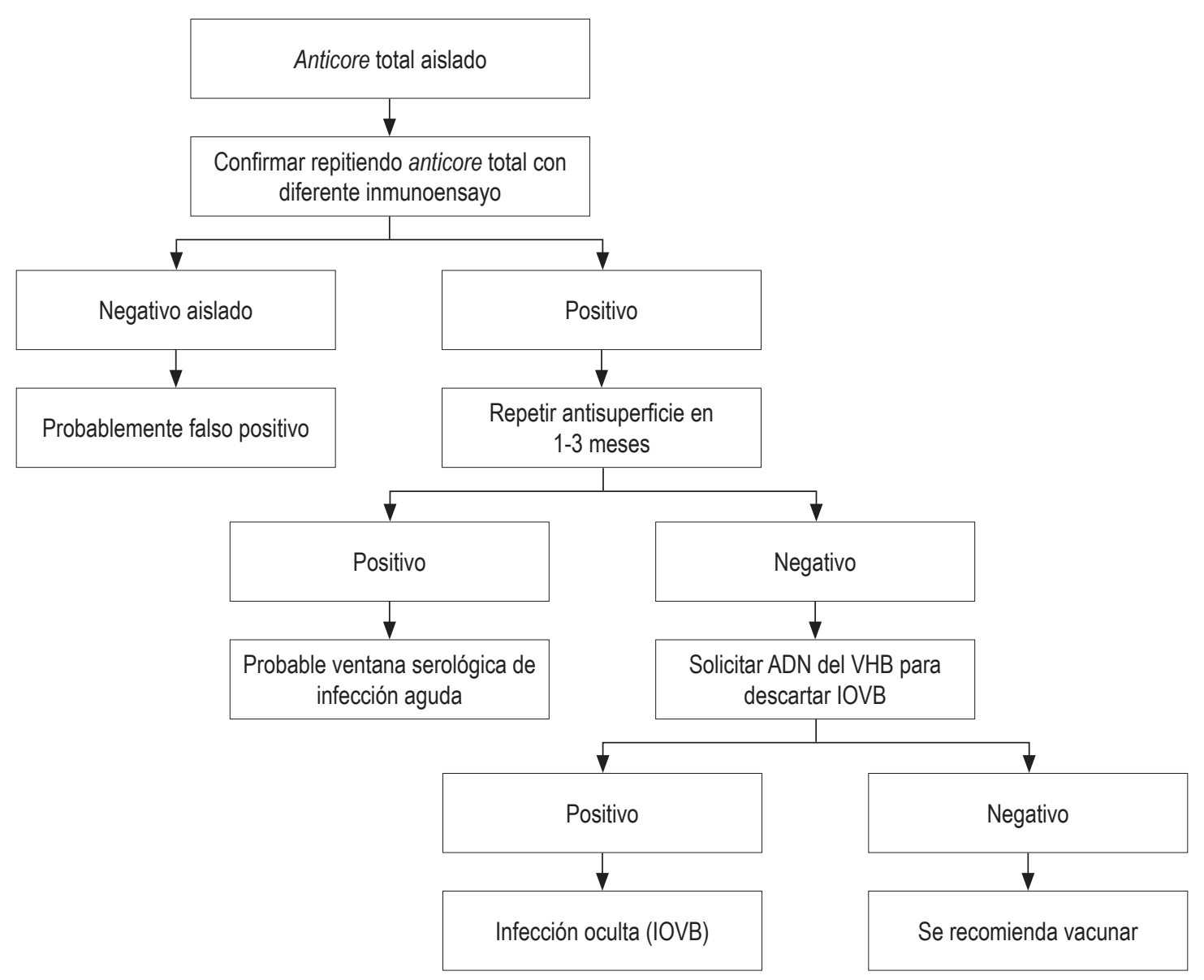

Figura 2. Evaluación de anticore positivo. Modificado de: Pondé RA et al. Arch Virol. 2010;155(2):149-58.

Tabla 4. Recomendaciones de asociaciones científicas

\begin{tabular}{lcccc}
\hline \multicolumn{1}{c}{ Asociaciones } & HBsAg & Anticore & Antisuperficie & ADN VHB \\
\hline CDC & Sí & Sí & Sí & No \\
AASLD & Sí, alto riesgo & Sí, alto riesgo & No & No \\
EASL & Sí & Sí & Sí & No \\
APSL & Sí & No & No & No \\
ASCO & Sí, alto riesgo & Sí, alto riesgo & No & No \\
AGA & Sí & Sí & No & \\
\hline
\end{tabular}

AASLD: Sociedad Americana para el Estudio de las Enfermedades del Hígado; AGA: Asociación Americana de Gastroenterología; APSL: Asociación del Pacífico Asiático para el estudio del Hígado; ASCO: Sociedad Americana de Oncología Clínica; CDC: Centro para el Control de Enfermedades.

tiene una altísima prevalencia: alrededor del $30 \%$ (71). Con base en evidencia publicada, a todos los pacientes que vayan a ser sometidos a quimioterapia o inmunosupresión se les debería solicitar HBsAg, anticore total y anticuerpos antisuperficie. Si tienen anticore positivo aislado, debe solicitarse ADN (72-74). Esas recomendaciones también son válidas para los pacientes que tengan enfermedades concomitantes que alteren la inmunidad (72-74). El riesgo de reactivación depende del perfil serológico y del tipo de quimioterapia. Los esquemas de inmunosupresión que 
más inducen reactivación son los que incluyen rituximab, un anticuerpo monoclonal quimérico contra la proteína CD20, expresada principalmente en la membrana plasmática de las células B (74-77). Recientemente, la AGA ha publicado las guías sobre inmunosupresión e infección por el VHB, en la cual se dan recomendaciones con base en la estratificación del riesgo de reactivación $(68,69)$. En las Figuras 3, 4 y 5 se presentan las recomendaciones (72).

Si el HBsAg es positivo y no se hace profilaxis antiviral, el riesgo de reactivación es de $30 \%-80 \%$ y se debe dar tratamiento con adefovir o entecavir (73). El origen de la reactivación es el $\mathrm{ADNccc}$. El nivel de los anticuerpos antisuperficie disminuye el riesgo de reactivación $(68,69)$. En un estudio se encontró que ninguno de los 10 pacientes con niveles de anticuerpos antisuperficie por encima de $100 \mathrm{UI} / \mathrm{mL}$ tuvo reactivación del VHB (74). La reactivación se identifica por los cambios en el ADN y la ALT (68). En los pacientes con $\mathrm{HBsAg}$ positivo con anticore positivo y ADN positivo, la reactivación se confirma si el ADN se eleva 1 Log ( 10 veces) o el ADN se hace positivo si antes era negativo $(69,76)$. La ALT se puede elevar 3 o más veces por encima del límite superior normal. Cuando esas enzimas se elevan, los pacientes tienen un peor pronóstico (76). Las manifestaciones clínicas de la reactivación van desde un cuadro asintomático hasta insuficiencia hepática aguda y muerte $(76,77)$. La recomendación de la AGA es dar tratamiento profiláctico, en vez de hacer seguimiento, con monitorización del ADN (68).
Cuando se hace monitorización y se espera la reactivación para dar tratamiento, la conducta se denomina tratamiento diferido (68). La reactivación también se puede presentar en pacientes que han tenido infección aguda resuelta, con evidencia serológica de cura funcional (HBsAg negativo, antisuperficie positivo con anticore positivo o negativo) (75-77). En esos casos, el VHB se puede reactivar en el $16 \%$, si reciben quimioterapia que contenga rituximab (75). En esos pacientes con infección resuelta, la recomendación es monitorizar el $\mathrm{ADN}$ viral cada 4 semanas y si aparece (se vuelve positivo), debe darse terapia para el VHB (76). Recientemente, en pacientes de ese tipo se comparó la estrategia de monitorización frente al tratamiento profiláctico (78). A los 18 meses de seguimiento, hubo reactivación en $3 / 28$ pacientes del grupo de monitorización frente a $0 / 33$ de quienes recibieron terapia profiláctica con tenofovir (78). Aunque la diferencia no fue estadísticamente significativa, se necesita un estudio con mayor tamaño de muestra para determinar cuál es la mejor opción o si no hay diferencias. En ese último caso, la elección dependerá del costo de los medicamentos frente a la determinación del ADN cada 4 semanas.

En los pacientes que tienen marcadores de infección, la recomendación es antivirales contra el VHB, como se mencionó. Los medicamentos recomendados son adefovir $\mathrm{y}$ entecavir, por su baja capacidad parta inducir resistencia del VHB. No obstante el alto riesgo de reactivación, la disponibilidad de guías de práctica clínica sobre el tema

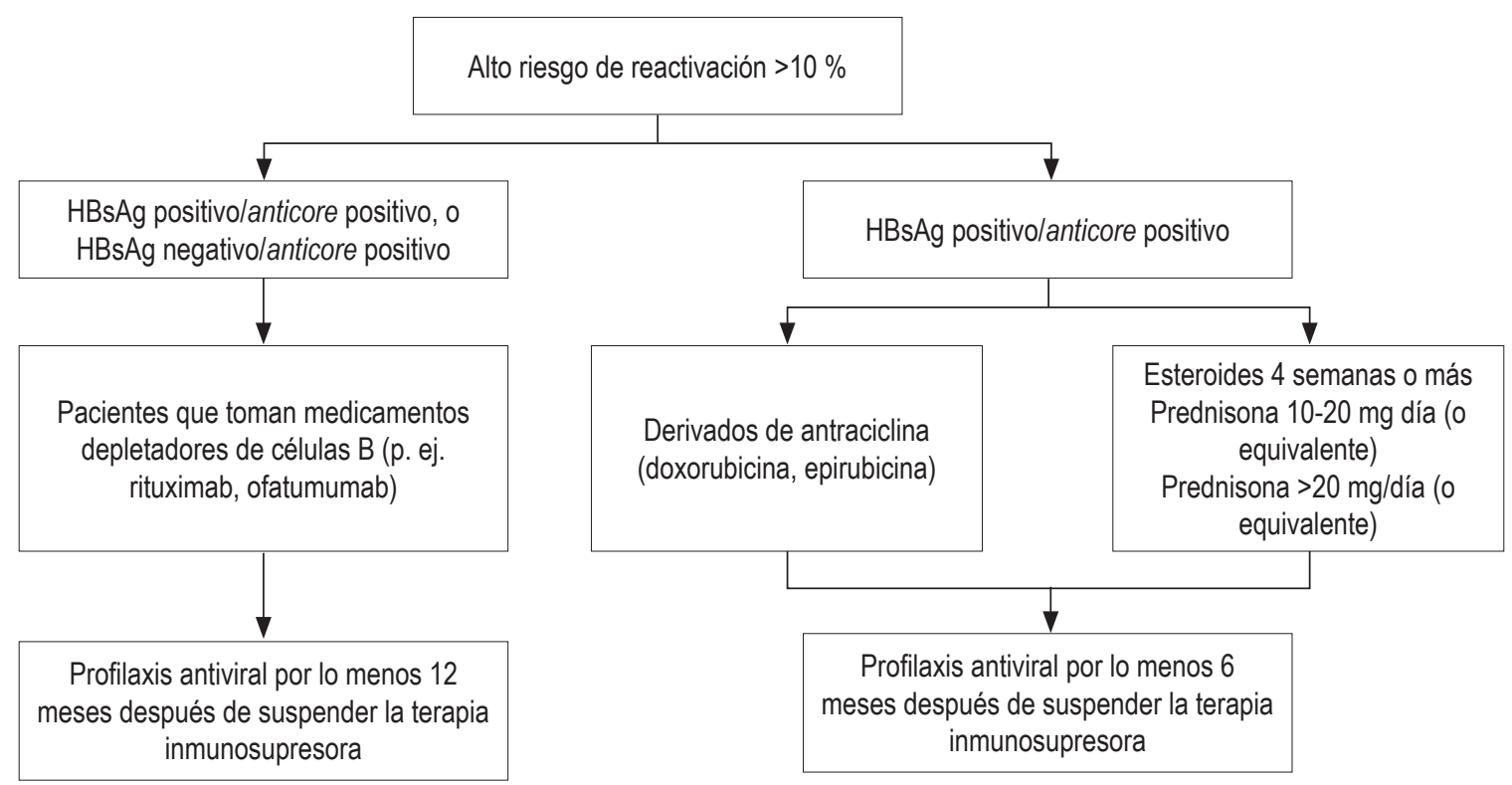

Figura 3. Pacientes con alto riesgo de reactivación del VHB. Modificado de: American Gastroenterological Association. Gastroenterology. 2015;148(1):220. 


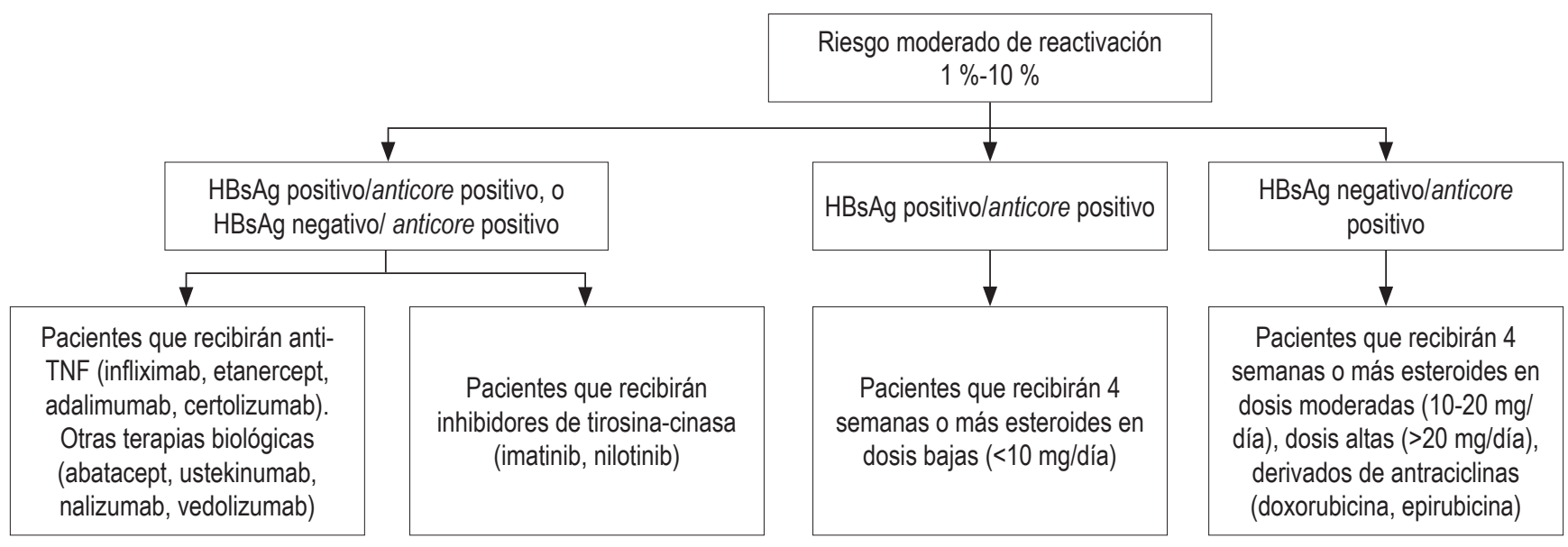

Terapia antiviral por lo menos hasta 6 meses después de suspender la inmunosupresión

Figura 4. Pacientes con riesgo moderado de reactivación del VHB. anti-TNF: inhibidor del factor de necrosis tumoral. Modificado de: American Gastroenterological Association. Gastroenterology. 2015;148(1):220.

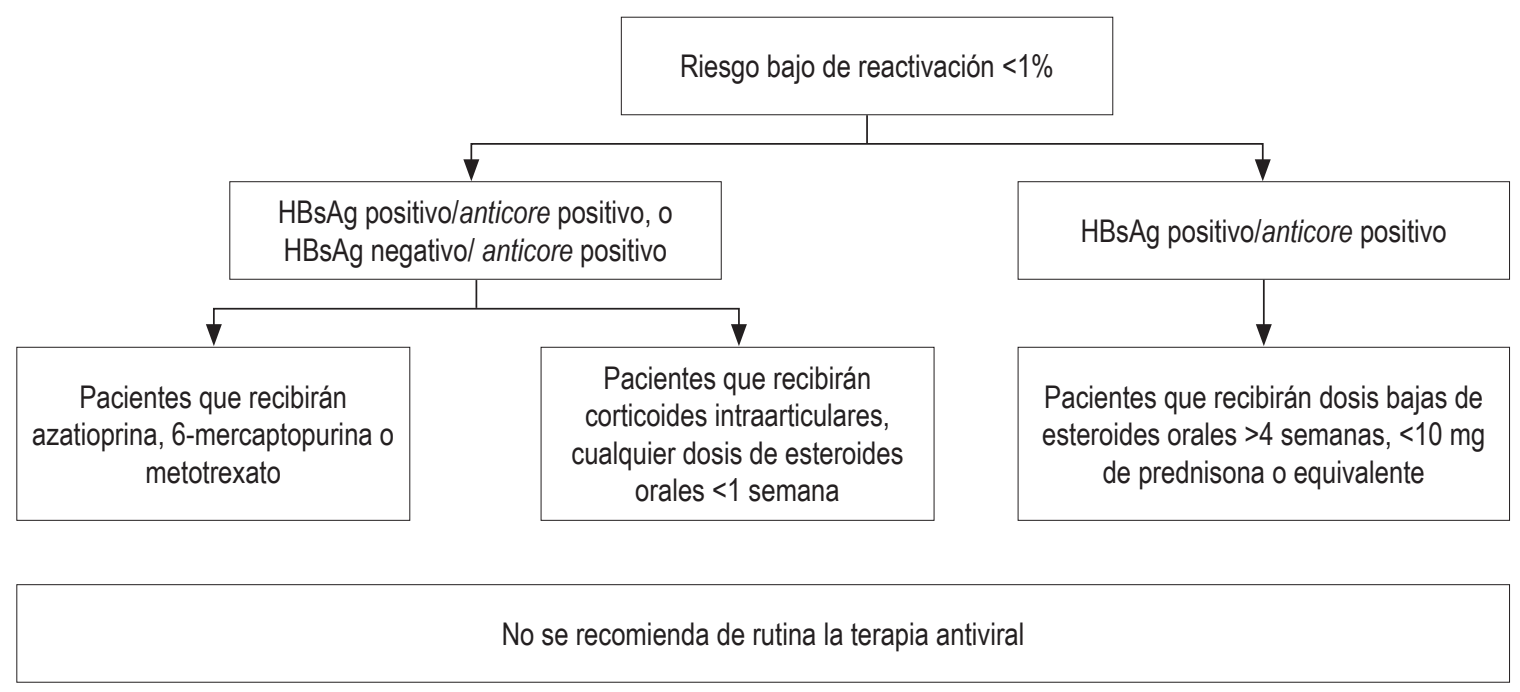

Figura 5. Pacientes con bajo riesgo de reactivación. Modificado de: American Gastroenterological Association. Gastroenterology. 2015;148(1):220.

$(68,75)$ y la investigación del VHB entre los oncólogos de Estados Unidos es subóptima (79).

\section{OTROS MARCADORES DE LA INFECCIÓN POR EL VHB}

\section{Antígeno relacionado con el core del VHB (AgRC)}

Este es un nuevo marcador de la infección por VHB que permite monitorizar y ayudar a establecer su pronóstico
(80). Se describió por primera vez en 2002 (81). Su concentración sérica tiene excelente correlación con el $\mathrm{ADN}$ del VHB en la sangre y, comparado con este, es superior para determinar la replicación viral y el ADNccc intrahepático (82). El ADN y el HBsAg en sangre son un reflejo del ADNccc intrahepático; sin embargo, el AgRC es más sensible que esos 2 marcadores clásicos. El $78 \%$ de los pacientes que tienen $\mathrm{ADN}$ negativo por el tratamiento antiviral sigue teniendo positivo el AgRC (83). En otro estudio, Lai y cola- 
boradores (84) encontraron que el $51 \%$ de los pacientes en quienes se negativizó el ADN por el tratamiento tenía ADNccc positivo en el hígado.

Similares al anterior, otros estudios han demostrado que no hay correlación entre la desaparición del $\mathrm{ADN}$ en suero y la desaparición del ADNccc intrahepático (80). En cambio, el AgRC es un mejor reflejo del ADNccc (80). En pacientes con $\mathrm{HBs} A g$ negativo y anticore positivo, con $\mathrm{ADN}$ negativo y AgRC positivo al recibir quimioterapia, la tasa de reactivación puede llegar al $40 \%$ (85). Por la mayor sensibilidad del AgRC como marcador del ADNccc, se le considera una nueva y muy prometedora herramienta, que permitiría monitorizar mejor el tratamiento de la infección crónica por el VHB, así como también de mucha utilidad en la IOVB y para la monitorización de la reactivación del VHB (80).

\section{Conflicto de intereses}

Ninguno.

\section{Agradecimientos}

Los autores agradecen inmensamente a la doctora Sandra Rubiano y al doctor Walter Chávez, excelentes internistas y docentes de Colombia, por la lectura crítica del manuscrito inicial y por sus recomendaciones, que permitieron mejorar notablemente este trabajo.

\section{REFERENCIAS}

1. World Health Organization. Global health sector strategy on viral hepatitis 2016-2021. [internet] 2018 [acceso el 1 de marzo de 2018]. Disponible en: https://www.who.int/ hepatitis/strategy2016-2021/ghss-hep/en/

2. World Health Organization. Hepatitis B. [internet] 2018 [acceso el 1 de marzo de 2018]. Disponible en: https:// www.who.int/news-room/fact-sheets/detail/hepatitis-b

3. Stanaway JD, Flaxman AD, Naghavi M, Fitzmaurice C, Vos T, Abubakar I, et al. The global burden of viral hepatitis from 1990 to 2013: findings from the Global Burden of Disease Study 2013. Lancet. 2016:388;1081-8.

4. Peeridogaheh H, Meshkat Z, Habibzadeh S, Arzanlou M, Shahi JM, Rostami S, et al. Current concept on immunopathogesis of hepatitis B virus infection. Vir Res. 2018;245:29-43. doi: 10.1016/j.virusres.2017.12.007.

5. Sandhu P, Haque M, Humphries-Bickley T, Ravi S, Song J. Hepatitis B virus immunopathology, model systems, and current therapies. Front Immunol. 2017;8: Article 436. doi: 10.3389/fimmu.2017.00436.

6. Li X, Zhao J, Yuan Q, Xia N. Detection of HBV Covalently Closed Circular DNA. Viruses. 2017;9(6). pii: E139. doi: $10.3390 / \mathrm{v} 9060139$.
7. Valaydos ZS, Locarnini SA. The virological aspects of hepatitis B. Best Pract Res Clin Gastroenterol. 2017;31:257-64. doi: 10.1016/j.bpg.2017.04.013.

8. Yang S, Wang D, Zhang Y, Yu C, Ren J, Xu K, et al. Transmission of Hepatitis B and C Virus Infection Through Body Piercing: A Systematic Review and Meta-Analysis. Medicine (Baltimore). 2015;94(47):e1893. doi: 10.1097/ MD.0000000000001893.

9. Yuen MF, Ahn SH, Chen DS, Chen PJ, Dusheiko GM, Hou $\mathrm{JL}$, et al. Chronic hepatitis B virus infection. Disease revisited and management recommendations. J Clin Gastroenterol. 2016;50:286-94. doi: 10.1097/MCG.0000000000000478.

10. Fattocich G, Bortolotti F, Donato F. Natural history of chronic hepatitis B: special emphasis on disease progression and prognostic factors. J Hepatol. 2008;48:335-52. doi: 10.1016/j.jhep.2007.11.011.

11. Schweitzer A, Horn J, Mikolajczyk RT, Krause G, Ott JJ. Estimations of 2080 worldwide prevalence of chronic hepatitis B virus infection: A systematic 2081 review of data published between 1965 and 2013. Lancet 2015;386:154655. doi: 10.1016/S0140-6736(15)61412-X.

12. Lozano R, Naghavi M, Foreman K, Lim S, Shibuya K, Aboyans V, et al. Global and regional mortality from 235 causes of death for 20 age groups in 1990 and 2010: A systematic analysis for the Global Burden of Disease Study 2010. Lancet. 2012;380:2095-128. doi: 10.1016/S01406736(12)61728-0.

13. Seeger C, Mason W. Molecular biology of hepatitis B virus infection. Virology. 2015;479-480:672-86. doi: 10.1016/j. virol.2015.02.031.

14. Trepo C, Chan H, Lok A. Hepatitis B virus infection. Lancet. 2014;384 (9959):2053-63. doi: 10.1016/S01406736(14)60220-8.

15. Villar LM, Medina-Cruz H, Ribeiro-Barbosa J, Souz-Bezerra C, Machado-Portilho M, Scalioni L. Update on hepatitis B and C virus diagnosis. World J Virol. 2015;4(4):323-42. doi: 10.5501/wjv.v4.i4.323.

16. Pondé RAA. Acute hepatitis B virus infection or cute exacerbation of chronic hepatitis B infection: the differential serological diagnosis. Eur J Clin Microbiol Infect Dis. 2016;35:29-40. doi: 10.1007/s10096-015-2522-7.

17. Durantel D. New treatments to reach functional cure: virological approaches. Best Pract res Clin Gastroenterol 2017;31:329-36. doi: 10.1016/j.bpg.2017.05.002.

18. Valaydon ZS, Locarnini SA. The virological aspects of hepatitis B. Best Pract Res Clin Gastroenterol. 2017;31:257-64. doi: 10.1016/j.bpg.2017.04.013.

19. Hong X, Kim ES, Guo H. Epigenetic regulation of hepatitis B virus covalently closed circular DNA: implications for epigenetic therapy against chronic hepatitis B. Hepatology 2017;66(6):2066-77. doi: 10.1002/hep.29479.

20. Durantel D, Zoulim F. New antiviral targets for innovative treatment concepts for hepatitis B virus and hepatitis delta virus. J Hepatol. 2016;64:S117-31. doi: 10.1016/j. jhep.2016.02.016. 
21. Zeisel MB, Lucifora J, Mason WS, Sureau C, Beck J, Levrero $\mathrm{M}$, et al. Towards an HBV cure: state of the art and unresolved questions-report of the ANRS workshop on HBV cure. Gut. 2015;64(8):1314-26. doi: 10.1136/gutjnl-2014-308943.

22. Schreiner S, Nassal M. A role for the host DNA damage response in hepatitis B virus cccDNA formation and beyond? Viruses. 2017;9(5):125. doi: 103390/v9050125.

23. Han Y, Tang Q, Zhu W, Zhang Y, You L. Clinical, biochemical, immunological and virological profiles of and differential diagnosis between, patients with acute hepatitis B and chronic hepatitis B with acute flare. J Gastroenterol Hepatol. 2008;23:1728-33. doi: 10.1111/j.1440-1746.2008.05600.x.

24. Kumar M, Jain S, Sharma BC, Sarin SK. Differentiating acute hepatitis B from the first episode of symptomatic exacerbation of chronic hepatitis B. Dig Dis Sci. 2006;51(3):594-9. doi: $10.1007 /$ s10620-006-3175-2.

25. Lin CJ, Kao JH. Natural history of acute and chronic hepatitis B: the role of $\mathrm{HBV}$ genotypes and mutants. Best Pract Res Clin Gastroenterol. 2017;31:249-55. doi: 10.1016/j. bpg.2017.04.010.

26. Beasley RP. Rocks along the road to the control of $\mathrm{HBV}$ and HCC. Ann Epidemiol 2009; 19:231-4. doi: 10.1016/j.annepidem.2009.01.017.

27. Sherlock S. The natural history of hepatitis B. Postgrad Med J. 1987;63:7-11.

28. European Association for the Study of the Liver. EASL 2017 Clinical Practice Guidelines on the management of hepatitis B virus infection. J Hepatol 2017;67:370-98. doi: 10.1016/j. jhep.2017.03.021.

29. Cacciola I, Pollicino T, Squadrito G, Cerenzia G, Orlando $\mathrm{ME}$, Raimondo G. Occult hepatitis B virus infection in patients with chronic hepatitis C liver disease. N Engl J Med. 1999;341:22-6. doi: 10.1056/NEJM199907013410104.

30. Raimondo G, Allain JP, Brunetto MR, Buendía MA, Chen DS, Colombo M, et al. Statements from the Taormina expert meeting on occult hepatitis B virus infection. J Hepatol. 2008;49:652-7. doi: 10.1016/j.jhep.2008.07.014.

31. Kwak MS, Kim YJ. Occult hepatitis B virus infection. World J Hepatol. 2014;6(12):860-9. doi: 10.4254/wjh.v6.i12.860.

32. Kang SY, Kim MH, Lee WI. The prevalence of "ati-HBc alone" and HBV DNA detection among anti $-\mathrm{HBc}$ alone en Korea. J Med Virol. 2010;82:16508-14. doi: 10.1002/ jmv.21862.

33. Yuen MF, Lee CK, Wong DK, Fung J, Hung I, Hau A, et al. Prevalence of occult hepatitis B infection in a highly endemic area for chronic hepatitis B: a study of a large blood donor population. Gut 2010; 59:1389-93. doi: 10.1136/ gut.2010.209148.

34. Makvandi M. Update on occult hepatitis B virus infection World J Gastroenterol. 2016;22(39):8720-34. doi: 10.3748/wjg.v22.i39.8720.

35. Sagnelli C, Macera M, Pisaturo M, Zampino R, Coppola M, Sagnelli E. Occult HBV infection in the oncohematological setting. 2016; 44(5):575-82. doi: 10.1007/s15010-0160891-1.
36. Zerbini A, Pilli M, Boni C, Fisicaro P, Penna A, Di VP, et al. The characteristics of the cell-mediated immune response identify different profiles of occult hepatitis B virus infection. Gastroenterology 2008; 134:1470-81. doi: 10.1053/j. gastro.2008.02.017.

37. Mulrooney-Cousins PM, Michalack TI. Persistent occult hepatitis B virus infection:experimental findings and clinical implications. World J Gastroenterol. 2007;13:5682-6. doi: 10.3748/wjg.v13.i43.5682.

38. Raimondo G, Caccamo G, Filomia R, Pollicino T. Occult HBV infection. Sem Immunopathol. 2013;35:39-52. doi: 10.1007/s00281-012-0327-7.

39. Mohsen W, Levy MT. Hepatitis A to E: what's new? Intern Med J. 2017;47:380-9. doi: 10.1111/imj.13386.

40. Gisbert JP, Chaparro M, Esteve M. Review article: prevention and management of hepatitis $\mathrm{B}$ and $\mathrm{C}$ infection in patients with inflammatory bowel disease. Aliment Pharmacol Ther 2011; 33:619-33. doi: 10.1111/j.13652036.2010.04570.x.

41. Melmed GY. Vaccination strategies for patients with inflammatory bowel disease on immunomodulators and biologics. Inflam Bowel Dis. 2009;15:1410-6. doi: 10.1002/ ibd.20943.

42. Squadrito G, Spinella R, Raimondo G. The clinical significance of occult HBV infection. Ann Gastroenterol. 2014;27(1):15-9.

43. Fabbri G, Mastrorosa I, Vergori A, Mazzotta V, Pinnetti C, Grisetti $S$, et al. Reactivation of occult HBV infection in an $\mathrm{HIV} / \mathrm{HCV}$ co-infected patient successfully treated with sofosbuvir/ledipasvir: a case report and review of the literature. BMC infect Dis. 2017; 17:182. doi: 10.1186/s12879017-2287-y.

44. Chen G, Wang C, Chen J, Ji D, Wang Y, Wu V, et al. Hepatitis $B$ reactivation in hepatitis $B$ and $C$ coinfected patients treated with antiviral agents: a systematic review and metaanalysis. Hepatology. 2017;66(1):13-26. doi: 10.1002/ hep.29109.

45. Perrillo RP. Hepatitis B virus reactivation during directacting antiviral treatment of chronic hepatitis C: A hidden danger of an otherwise major success story. Hepatology. 2017;66(1):4-6. doi: 10.1002/hep.29185.

46. Food and Drug Administration. FDA Drug Safety Communication: FDA warns about the risk of hepatitis B reactivating in some patients treated with direct-acting antivirals for hepatitis C. FDA [internet] 2016 [acceso el 27 de diciembre de 2017]. Disponible en: http://www.fda.gov/ downloads/Drugs/DrugSafety/UCM523499.pdf.

47. Zhou K, Terrault N. Management of hepatitis B in special populations. Best Pract Res Clinl Gastroenterol. 2017;31:311-20. doi: 10.1016/j.bpg.2017.06.002.

48. Milich DR, McLachlan A. The nucleocapsid of hepatitis B virus is both a T-cell-independent and a T-cell-dependent antigen. Science. 1986;234:1398-1401. doi: 10.1126/ science.3491425. 
49. Busch MP. Should HBV DNA NAT replace HBsAg and/ or anti-HBc screening of blood donors? Tranfus Clin Biol. 2004;11(1):26-32. doi: 10.1016/j.tracli.2003.12.003.

50. Wang Q, Klenerman P, Semma N. Significance of anti$\mathrm{HBc}$ alone serological status in clinical practice. Lancet Gastroenterol Hepatol. 2017;2(2):123-34. doi: 10.1016/ S2468-1253(16)30076-0.

51. Wu T, Kwok RM, Tran TT. Isloated anti HBc: the relevance of hepatits B core antibody: a review of new issues. Am J Gastroenterol 2017;112:1780-8. doi: 10.1038/ ajg.2017.397.

52. Marusawa H, Uemoto S, Hijikata M, Ueda Y, Tanaka K, Shimotohno K, et al. Latent hepatitis B virus infection in healthy individuals with antibodies to hepatitis B core antigen. Hepatology. 2000;31(2):488-95. doi: 10.1002/ hep.510310232.

53. Berger A, Doerr HW, Rabenau HF, Weber B. High frequency of HCV infection in individuals with isolated antibody to hepatitis B core antigen. Intervirology 2000;43:71-6. doi: 10.1159/000025026.

54. Marusawa H, Osaki Y, Kimura T, Ito K, Yamashita Y, Eguchi $\mathrm{T}$, et al. High prevalence of anti-hepatitis $\mathrm{B}$ virus serological markers in patients with hepatitis $\mathrm{C}$ virus related chronic liver disease in Japan. Gut. 1999;45(2):284-8. doi: 10.1136/ gut.45.2.284.

55. Jilg W, Sieger E, Zachoval R, Schätzl H. Individuals with antibodies against hepatitis $\mathrm{B}$ core antigen as the only serological marker for hepatitis B infection: high percentage of carriers of hepatitis B and C virus. J Hepatol. 1995;23(1):14-20.

56. Wedemeyer $\mathrm{H}$, Cornberg M, Tietmeyer B. Isolated anti-HBV core phenotype in anti-HCV-positive patients is associated with hepatitis C virus replication. Clin Microbiol Infect. 2004;10:70-2. doi: 10.1111/j.1469-0691.2004.00771.x.

57. Chu CM, Yeh CT, Liaw YF. Low-level viremia and intracellular expression of hepatitis B surface antigen ( $\mathrm{HBsAg}$ ) in $\mathrm{HBsAg}$ carriers with concurrent hepatitis $\mathrm{C}$ virus infection. J Clin Microbiol. 1998;36:2084-6.

58. Wagner AA, Denis F, Weinbreck P, Loustaud V, Autofage F, Rogez S, et al. Serological pattern 'anti-hepatitis B core alone' in HIV or hepatitis C virus-infected, patients is not fully explained by hepatitis B surface antigen mutants. AIDS. 2004;18(3):569-71. doi: 10.1097/00002030-20040220000028.

59. Piroth L, Binquet C, Vergne M, Minello A, Livry C, Bour $\mathrm{JB}$, et al. The evolution of hepatitis $\mathrm{B}$ virus serological patterns and the clinical relevance of isolated antibodies to hepatitis B core antigen in HIV infected patients. J Hepatol. 2002;36(5):681-6.

60. Loustaud-Ratti V, Wagner A, Carrier P, Marczuk V, Chemin I, Lunel F, et al. Distribution of total DNA and cccDNA in serum and PBMCs may reflect the HBV immune status in $\mathrm{HBsAg}+$ and HBsAg- patients coinfected or not with HIV or HCV. Clin Res Hepatol Gastroenterol. 2013;37(4):37383. doi: 10.1016/j.clinre.2012.11.002.
61. Pondé RA, Cardoso DD, Ferro MO. The underlying mechanisms for the 'anti-HBc alone' serological profile. Arch Virol. 2010;155(2):149-58. doi: 10.1007/s00705-009-0559-6.

62. Parkinson AJ, McMahon BJ, Hall D, Ritter D, Fizgerald MA. Comparison of enzyme immunoassay with radioimmunoassay for the detection of antibody to hepatitis core antigen as the only marker of hepatitis B infection in a population with a high prevalence of Hepatitis B. J Med Virol. 1990;30:2537. doi: $10.1002 /$ jmv.1890300405.

63. Silva AE, McMahon BJ, Parkinson AJ, Sjögren $\mathrm{MH}$, Hoofnagle JH, Di Bisceglie AM. Hepatitis B virus DNA in persons with isolated antibody to hepatitis $\mathrm{B}$ core antigen who subsequently received hepatitis B vaccine. Clin Infect Dis. 1998;26:895-7. doi: 10.1086/513918.

64. Galbraith RM, Eddleston AL, Williams R, Zuckerman AJ. Fulminant hepatic failure in leukaemia and choriocarcinoma related to withdrawal of cytotoxic drug therapy. Lancet. 1975;2:528-30. doi: 10.1016/S0140-6736(75)90897-1.

65. Nagingthon J. Reactivation of hepatitis B after transplantation operations. Lancet. 1977;1:558-60. doi: 10.1016/ S0140-6736(77)91995-X.

66. Martinot-Peignoux M, Asselah T, Marcellin P. HBsAg Quantification to Optimize Treatment Monitoring in Chronic Hepatitis B Patients. Liver Int. 2015;35(Suppl 1):82-90. doi: 10.1111/liv.12735.

67. Di Bisceglie AM, Lok AM, Martin P, Terrault N, Perillo RP, Hoofnagle JH. Recent US Food and Drug Administration warnings on hepatitis $B$ reactivation with immune-suppresing and anticancer drugs: just the tip of the iceberg?. Hepatology. 2015;61(2):703-11. doi: 10.1002/hep.27609.

68. Perrillo RP, Gish R, Falck-Ytter YT. American Gastroenterological Association Institute technical review on prevention and treatment of hepatitis B virus reactivation during immunosuppressive drug therapy. Gastroenterology. 2015;148:221-44. doi: 10.1053/j.gastro.2014.10.038.

69. Reddy KR, Beavers KL, Hammond SP, Lim JK, Falck-Ytter Y. American Gastroenterological Association Institute Guideline on the prevention and treatment of hepatitis B virus reactivation during immunosuppressive drug therapy. Gastroenterology 2015; 148:215-9. doi: 10.1053/j.gastro.2014.10.039.

70. Bessone F, Dirchwolf M. Management of hepatitis B reactivation in immunosupressed patients: an update on current recommendations. World J Hepatol. 2016;8(8)385-94. doi: 10.4254/wjh.v8.i8.385.

71. Lau GKK. How do we handle the ant-HBc positive patient (in highly endemic settings): The Anti-HBc positive patient. Clinical Liver Disease 2015;5:29-31. doi: 10.1002/cld.399.

72. American Gastroenterological Association. AGA Institute guidelines on Hepatitis $\mathrm{B}$ reactivation $(\mathrm{HBVr})$ : Clinical Decision Support Tool. Gastroenterology. 2015;148(1):220. doi: 10.1053/j.gastro.2014.11.040.

73. Paul S, Dickstein A, Saxena A, Terrin N, Viveiros K, Balk EM, et al. Role of Surface antibody in hepatitis B reactivation in patients with resolved infection and hematologic 
malignancy: a meta-analysis. Hepatology 2017;66 (2):37988. doi: 10.1002/hep.29082.

74. Pei SN, Ma MC, Wang MC, Kuo CY, Rau KM, Su CY, et al. Analysis of hepatitis B surface antibody titers in B cell lymphoma patients after rituximab therapy. Ann Hematol. 2012;91(7):1007-12. doi: 10.1007/s00277-012-1405-6.

75. Mozessohn L, Chan KK, Feld JJ, Hicks LK. Hepatitis B reactivation in $\mathrm{HBs}$ Ag-negative/ $\mathrm{HBcAb}$-positive patients receiving rituximab for lymphoma: a meta-analysis. J Viral Hepat. 2015;22:842-9. doi: 10.1111/jvh.12402.

76. Loomba R, Liang TJ. Hepatitis B Reactivation Associated With Immune Suppressive and Biological Modifier Therapies: Current Concepts, Management Strategies, and Future Directions. Gastroenterology. 2017;152(6):1297309. doi: 10.1053/j.gastro.2017.02.009.

77. Paul S, Saxena A, Terrin N, Viveiros K, Balk EM, Wong JB. Hepatitis $\mathrm{B}$ virus reactivation and prophylaxis during solid tumor chemotherapy: a systematic review and meta-analysis. Ann Intern Med 2016; 164:30-40. doi: 10.7326/M15-1121.

78. Buti M, Manzano ML, Morillas RM, García-Retortillo M, Martín L, Prieto M, et al. Randomized prospective study evaluating tenofovir disoproxil fumarate prophylaxis against hepatitis $B$ virus reactivation in anti $\mathrm{HBc}$-positive patients with rituximab-based regimens to treat hematologic malignancies: the PREBLIN study. Plon One. 2017;12(9):e0184550. doi: 10.1371/journal. pone. 0184550 .
79. Kwak YE, Stein SM, Lim JK. Practice Patterns in Hepatitis B Virus Screening Before Cancer Chemotherapy in a Major US Hospital Network. Dig Dis Sci. 2018;63(1):61-71. doi: 10.1007/s10620-017-4850-1.

80. Mak LY, Wong DKH, Cheung KS, Seto WK, Lai CL, Yiuen MF. Hepatitis B core-related antigen (HBcrAg): an emerging marker for chronic hepatitis B virus infection. Aliment Pharmacol Ther. 2018;47:43-54. doi: 10.1111/apt.14376.

81. Ji M, Hu K. Recent advances in the study of hepatitis B virus covalently closed circular DNA. Virol Sin. 2017;32(6):454464. doi: 10.1007/s12250-017-4009-4.

82. Kimura T, Rojuhara A, Sakamoto Y. Sensitive enzyme immunoassay for hepatitis B virus core-related antigens and their correlation to virus load. J Clin Microbiol. 2002;40:439-45. doi: 10.1128/JCM.40.2.439-445.2002.

83. Wang DK, Seto WK, Cheung KS. Hepatitis B virus corerelated antigen as a surrogate marker for covalently closed circular DNA. Liver Intern. 2017;37:995-1001. doi: 10.1111/liv.13346.

84. Lai CL, Wong DP. Reduction of covalently closed circular DNA with long-term nucleos $(\mathrm{t})$ ide analogue treatment in chronic hepatitis B. J Hepatol. 2017;66:275-1. doi: 10.1016/j.jhep.2016.08.022.

85. Yeo W, Chan PK, Zhong S, Ho WM, Steinberg JL, Tam JS, et al. Frequency of hepatitis B virus reactivation in cancer patients undergoing cytotoxic chemotherapy: a prospective study of 626 patients with identification of risk factors. J Med Virol. 2000;62(3):299-307. 